\title{
Sensitivity of predictions of merchantable tree height, log production, and lumber recovery to tree taper
}

\author{
by Chao Li $i^{1, *}$, Hugh Barclay², Shongming Huang ${ }^{3}$, Harinder Hans ${ }^{1}$ and Sirak Ghebremusse ${ }^{4}$
}

\begin{abstract}
Tree taper models characterize the change in diameter from the bottom to the top of a tree, thereby contributing to the estimation of tree volume. This paper examines the sensitivity of predictions of merchantable height defined as the tree height at a given top diameter inside bark (DIB) determined by the utilization standard, log production, and lumber recovery to the eight parameters in Kozak's (1988) tree taper model. We found that predictions of merchantable height and log production were sensitive to two parameters, whereas predictions of the percentage of lumber recovery were sensitive to one parameter. Because the three measures examined in this study are not very sensitive to tree taper, especially the percentage of lumber recovery that is of most concern to the forest industry, together with the relatively small variations in tree taper parameters across Canada and the limited contribution of tree taper to characterizing the value of lumber recovery at the stand scale, one could infer that it may be possible to develop a single Canadian national softwood tree taper model for predicting forest product variables such as log production and percentage of lumber recovery from forest inventory.
\end{abstract}

Keywords: Kozak’s taper model, tree height, log production, lumber recovery, response surface

\section{RÉSUMÉ}

Les modèles de défilement des arbres représentent la variation en diamètre de la souche à la cime de larbre, permettant ainsi destimer le volume de larbre. Cet article étudie la sensibilité des prédictions de la hauteur marchande définie comme étant la hauteur de l’arbre à un diamètre donné sans écorce (dsé) déterminée par la norme d'utilisation, la production de billot et le rendement en bois de sciage en fonction des huit paramètres du modèle de défilement de larbre de Kozak (1988). Nous avons relevé que les prédictions de la hauteur marchande et la production de billot étaient sensibles à deux paramètres, tandis que les prédictions du pourcentage de rendement en bois de sciage étaient sensibles à un seul paramètre. Compte tenu que les mesures prises sur les arbres utilisées au cours de cette étude ne sont pas très sensibles au défilement de larbre, surtout pour ce qui du pourcentage de rendement en bois de sciage qui est du plus grand intérêt pour lindustrie forestière, en plus du fait quon ne retrouve qu'une faible variation des paramètres de défilement des arbres au Canada et de la contribution limitée du défilement de larbre pour établir le rendement en bois de sciage à léchelle du peuplement, on pourrait conclure qu'il est probablement possible de développer un seul modèle de défilement pour les conifères du Canada qui prédirait les variables portant sur les produits forestiers comme la production de billot et le pourcentage de rendement en bois de sciage à partir d'un inventaire forestier.

Mots clés : modèle de défilement de Kozak, hauteur de larbre, production de billot, rendement en bois de sciage, surface de réponse

\section{Introduction}

Estimating forest products' potential yield from existing forest inventory is desirable in improving decision-making in optimal wood resources utilization. This estimation requires forest inventory as a basis, calculation of wood volume from the forest inventory, and assessment of wood product recovery from operations of different mills. Forest inventory can be compiled at different scales, such as sampling plots for research or ground-truthing in remote-sensing-based mapping, and the mapping products of regional or operational inventory for forest management planning. Utilization of tree taper models in estimating wood volume has been a common practice in forest management agencies and industries, and detailed procedures of this method can be found in Government manuals (e.g., BC Ministry of Forests, Lands and Natural Resource Operations 2012). The assessment of wood product recovery (rate) could be a challenging issue since it can vary significantly with differences in size distribution and quality of logs, types of forest products, and efficiencies of mill operations caused by equipment and their configuration. This study focused on combining calculation of wood volume using tree taper models and assessment of wood product recovery, to evaluate the sensitivity of predictions of merchantable tree height, log production, and lumber recovery to tree taper.

Tree taper has been defined as the change in stem diameter between two measurement points divided by the length of the stem between these two points (Morris and Forslund 1992), and is generally referred to as the rate of decrease in diameter with increasing height up the stem (Newnham 1992). From a forest product perspective, trees with a high degree of taper are considered to have poor form, whereas those with low taper are thought to have good form. Tree taper reflects the geometric shapes of trees, which are commonly neiloid at the base, paraboloid along

\footnotetext{
${ }^{1}$ Canadian Wood Fibre Centre, Canadian Forest Service, 5320 - 122 Street, Edmonton, Alberta T6H 3S5.

${ }^{2}$ Retired; formerly with Pacific Forestry Centre, Canadian Forest Service, 506 Burnside Road West, Victoria, British Columbia V8Z 1 M5.

${ }^{3}$ Alberta Environment and Sustainable Resource Development, 9920 - 108 Street, Edmonton, Alberta T5K 2M4.

${ }^{4}$ Formerly with Canadian Wood Fibre Centre, Canadian Forest Service, 5320 - 122 Street, Edmonton, Alberta T6H 3S5.

*Corresponding author. E-mail: Chao.Li@NRcan-RNCan.gc.ca
} 
the main part of the bole, and conoid at the top. The basic pattern whereby diameter inside bark (DIB) changes with tree height $(h)$ corresponds approximately to these geometric shapes: DIB decreases rapidly with increasing $h$ near the base of the tree; then the rate of decrease slows along the main part of the bole and increases again toward the tip of the tree. Various mathematical functions, called taper models, have been employed to characterize tree taper as DIB along $h$, and thus to calculate the merchantable tree height at a given diameter, and compute volumes.

The main application of taper models in forest inventory is to determine the volume of a part of stem of required log length/ diameter limits, and this volume can then be modified by decay, breakage and waste to obtain net volume (BC Ministry of Forests, Lands and Natural Resource Operations 2012). This application appears critical to forest management planning and to support the forest industries in determining strategies for wood utilization. In western Canada, for instance, the majority of harvested softwood timber is used in the lumber industry, such as for construction materials. As such, the harvested wood will be sent to sawmills first, with residues being sent to pulp mills or for use as biofuel. Our current study is aimed at exploring how existing research results from the field of taper models could be of greater use in the practice of the forest sector or in industryfrom predictions of wood volume to forest product potential.

The objective of this study was to investigate, by means of a standard sensitivity analysis, whether Kozak's tree taper model can serve as a generic form to be used in predicting speciesspecific merchantable tree height and log production, and producing log dimension data for use in Optitek (Forintek Canada Corp. 2006) simulations to predict lumber recovery; in other words, to explore the relative importance of the uncertainties involved in each of the parameters.

\section{Materials and Methods}

Basic form selection of the taper model

Two general approaches have been used to develop tree taper models. Earlier research efforts tended to consider various sections of the tree separately, developing a unique function for each section and connecting these functions smoothly at each join point (e.g., Ormerod 1973, Max and Burkhart 1976, Demaerschalk and Kozak 1977, Clark et al 1991, Maguire and Batista 1996, Leites and Robinson 2004, Jiang et al. 2007). The other approach is to develop a continuous function describing the profile of the tree stem along its entirety (e.g., Kozak 1988, 2004; Newnham 1988; Zakrzewski 1999; Bi 2000; Sharma and Zhang 2004).

Kozak's (1988) taper model (eq. 1, which will be referred to as Kozak's taper model hereafter), known as the "variableexponent taper equation", was adopted by the British Columbia Ministry of Forests in 1989 (Kozak 2004), and is also being used in Alberta (e.g., Huang 1994, Huang et al. 1999), Saskatchewan (e.g., Gal and Bella 1994), Manitoba (e.g., Klos et al. 2007), several places in the United States (e.g., Li et al. 2012), Europe (e.g., Hjelm 2011), and Asia (e.g., Wang et al. 2007). As a result, the use of Kozak's taper model has been commonly reported in the literature over the past couple of decades, and was chosen as the basic form of taper model in this study. It is:

[1] $D I B_{i}=a_{0} D B H^{a_{1}} a_{2}{ }^{D B H} X_{i}^{b_{1} Z_{i}^{2}+b_{2} \ln \left(Z_{i}+0.001\right)+b_{3} \sqrt{Z_{i}}+b_{4} e^{Z_{i}}+b_{5}(D B H / H)}$

where $D I B_{i}$ is the diameter inside bark at height $h_{i}$ in $\mathrm{cm}$; $H$ is the total tree height in $\mathrm{m} ; h_{i}$ is the tree height in $\mathrm{m}$ above the ground and within the tree, with $0 \leq h_{i} \leq H$; $Z_{i}$ is the relative height within the tree, with $Z_{i}=h_{i} / H$; $X_{i}=\left(1-\sqrt{h_{i} / H}\right) /(1-\sqrt{p}) ; p=(\mathrm{HI} / H) \times 100 ; \mathrm{HI}$ is the height of the inflection point, commonly taken to be $20 \%$ to $25 \%$ of the total height, for example, $22.5 \%$ is used in Alberta (Huang 1994); $D B H$ is diameter outside bark at breast height (i.e., $1.3 \mathrm{~m}$ ) in $\mathrm{cm}$; and $a_{0}, a_{1}, a_{2}, b_{1}, b_{2}, b_{3}, b_{4}$, and $b_{5}$ are parameters. This equation can provide flexible DIB vs. height curves with various combinations of parameters.

Kozak's taper model has been widely used to calculate DIB at various heights up the bole $\left(h_{i}\right)$, and it allows one to construct a virtual tree. Parameter estimation for Kozak's model is often based on a given set of data (usually from stem analysis), and the results may therefore differ for different tree species at different sites and for individual trees felled for stem analysis. However, Kozak (1988) found similarities in his results from 33 species groups from British Columbia and he reported data for four species groups in detail: coast Douglas-fir (Pseudotsuga menziesii [Mirb.]); western red cedar (Thuja plicata Donn ex D. Don,); interior lodgepole pine (Pinus contorta var. latifolia Engelm.); and black cottonwood (Populus trichocarpa Torr. \& A. Gray). Huang (1994) and Huang et al. (1999) also found many of the model parameters are quite similar from various studies for white spruce (Picea glauca [Moench] Voss) among different

Table 1. Characteristics of the parameters in Kozak's (1988) model for black spruce and softwood group in Alberta from Huang (1994]

\begin{tabular}{|c|c|c|c|c|c|c|c|c|}
\hline \multirow[b]{2}{*}{ Parameter } & \multicolumn{4}{|c|}{ Black spruce } & \multicolumn{4}{|c|}{ Softwood group } \\
\hline & Mean & $\operatorname{Max}$ & Min & $\operatorname{Std}^{\mathrm{a}}$ & Mean & $\operatorname{Max}$ & Min & Std $^{\mathrm{a}}$ \\
\hline$a_{0}$ & 0.94 & 0.96 & 0.93 & 0.01 & 0.87 & 0.91 & 0.84 & 0.03 \\
\hline$a_{1}$ & 0.96 & 0.97 & 0.95 & 0.01 & 1.00 & 1.02 & 0.97 & 0.02 \\
\hline$a_{2}$ & 1.00 & 1.00 & 1.00 & 0.00 & 1.00 & 1.00 & 1.00 & 0.00 \\
\hline$b_{1}$ & 1.33 & 1.43 & 1.24 & 0.10 & 1.02 & 1.14 & 0.84 & 0.14 \\
\hline$b_{2}$ & -0.33 & -0.31 & -0.36 & 0.03 & -0.24 & -0.22 & -0.25 & 0.01 \\
\hline$b_{3}$ & 2.74 & 2.95 & 2.54 & 0.21 & 1.68 & 1.83 & 1.58 & 0.11 \\
\hline$b_{4}$ & -1.34 & -1.22 & -1.46 & 0.12 & -0.80 & -0.69 & -0.91 & 0.09 \\
\hline$b_{5}$ & 0.15 & 0.15 & 0.15 & 0.00 & 0.12 & 0.17 & 0.07 & 0.04 \\
\hline$p$ & 0.23 & 0.23 & 0.23 & 0.00 & 0.23 & 0.23 & 0.23 & 0.00 \\
\hline
\end{tabular}

a Standard deviation. 

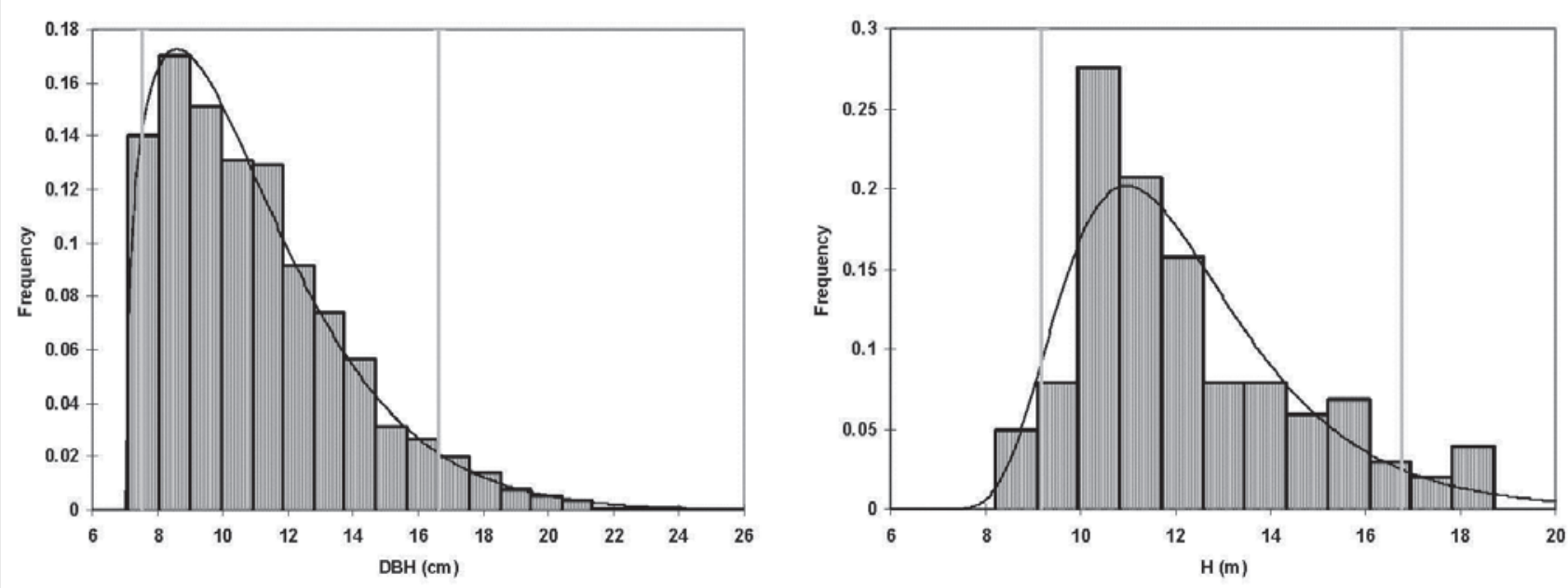

Fig. 1. Frequency distributions of diameter at breast height $(\mathrm{DBH})$ (left) and total height $(H)$ (right) of black spruce in the study area.

eco-regions across Alberta, as well as for other different major commercial tree species in Alberta. Table 1 summarizes the characteristics of each parameter of Kozak's taper model for black spruce (Picea mariana [Mill.] BSP), and the softwood group from Huang (1994), in which the tree species contained in the softwood group include not only black spruce, but also white spruce, lodgepole pine, Douglas-Fir, Engelmann spruce (Picea engelmannii Parry ex Engelm.), and Jack pine (Pinus banksiana Lamb.).

Muhairwe et al. (1994) investigated whether the predictive capabilities of Kozak's taper model could be improved by incorporating crown class, site class, and breast-height age into the exponential part of the model for Douglas-fir, western red cedar, trembling aspen (Populus tremuloides Mich.), and lodgepole pine. Apart from the use of crown ratio for lodgepole pine, they found that the additional variables resulted in only marginal improvements over the published version of Kozak's taper function. Therefore, they concluded that the cost of measuring these additional variables might not be justifiable. Kozak (1998) tested whether the variable-exponent taper model could be improved by an additional upper-stem measurement of outside bark diameter but reported that the improvements were small and statistically insignificant. However, the sensitivity of predictions of merchantable height, $h_{m}$, (i.e., the tree height at a given top DIB determined by a wood utilization standard), of the number of logs that can be produced, and of the recovery of lumber from the trees to values of the eight parameters in Kozak's tree taper model remains unclear.

The similarities of estimated parameters of the Kozak's taper model (Table 1) and the robustness of predictions (Muhairwe et al. 1994, Kozak 1998) suggested that this model might have the potential to serve as a generic description of tree form parameters for forest management planning at higher levels. To verify this possibility, a further examination of how the predicted variables could be affected by changes in either independent variables or model parameters would be required. The effect of independent variables on the robustness of predictions is usually investigated through the model validation process, which is "to see whether or not a fitted model gives an acceptable performance when it is used for prediction" using other sampling data (Huang et al. 1999). In the current study, we assess how the predicted variables (merchantable tree height, log production, and lumber recovery) could be affected by changes in model parameters via a sensitivity analysis.

\section{Data source, values for and relationship between DBH and $\mathrm{H}$ of black spruce}

Actual ranges of DBH and $H$ for black spruce were obtained from the forest inventory plot data for our study area, Forest Management License (FML) \#1 located in central-eastern Manitoba. The nominal total size of this FML is 889471 ha, of which about two-thirds is considered to be productive and potentially productive forest lands. Since April 2009, Nopiming Provincial Park has been excluded from harvesting in this FML, which has reduced the effective size of the FML by 142900 ha.

The forest inventory data are the best available information about forest conditions in the area (see <http://www.gov. $\mathrm{mb}$.ca/conservation/forestry/pdf/wood-supply/fmla_1_wood_ supply_report.pdf $>$, accessed 30 January 2012), and the operational forest inventory has been used for various levels of forest management planning and decision-making by both the provincial forest management agency (Manitoba Conservation) and forest industry (specifically Pine Falls Operations, Tembec Industries Inc., before its closure in Sept. 2010). The forest inventory plot data were collected from more than 700 polygons, each containing three plots. The area of each plot was 0.01 ha, and the $\mathrm{DBH}$ and $H$ for all trees with $\mathrm{DBH}$ greater than $7.1 \mathrm{~cm}$ were measured, which resulted in data for about 26000 trees in total, including 10338 black spruce.

The range of DBH for the black spruce in this database was $7.1 \mathrm{~cm}$ to $37.6 \mathrm{~cm}$ (average $11.7 \mathrm{~cm}$ ), and the range of $H$ was $3 \mathrm{~m}$ to $24.7 \mathrm{~m}$ (average $11.3 \mathrm{~m}$ ); the frequency distributions of these two variables are presented in Fig. 1.

The relationship between measurements of $\mathrm{DBH}$ and $H$ of black spruce in our study area was investigated by using the nonlinear regression analysis of SAS (SAS Institute Inc. 1990). Various formulas for the regression were fitted to the data, and only the result from the best fit is reported in this study. The $95 \%$ confidence band was also calculated for determining 
approximately realistic combinations of the $\mathrm{DBH}$ and $H$ of individual trees.

The DBH distribution data were fitted by the three parameter form of the Weibull probability density function:

$$
f(T)=\frac{\beta}{\eta}\left(\frac{T-\gamma}{\eta}\right)^{\beta-1} e^{-\left(\frac{T-\gamma}{\eta}\right)^{\beta}}
$$

where $f(T) \geq 0, T \geq 0$ or $\gamma, \beta>0, \eta>0,-\infty<\gamma<\infty$, and $\eta$ is the scale parameter, $\beta$ is the shape parameter, and $\gamma$ is the location parameter.

Eq. 2 was fitted using the black spruce measurements from the forest inventory plots in our study area by using the BestFit version 4.5 from the Palisade Decision Tools. Considering the minimal utilization standard of 60-year-old stands in Manitoba, the $\mathrm{DBH}$ distribution of black spruce with age older than 60 years can be best characterized by the probability distribution with parameters $\beta=1.1607, \eta=4.239$, and $\gamma=7.0824$. This fitted Weibull probability distribution for black spruce was used in our sensitivity analysis for lumber volume recovery at the stand scale.

\section{Calculation of merchantable height and log production using Kozak's taper model}

Kozak's taper model shows that the DIB monotonically decreases with increasing tree height up to the top of tree; thus, the merchantable height, $h_{m}$, was assumed $0<h_{m}<H$ and appeared only once. Therefore, the tree height $h_{i}$ corresponding to $\mathrm{DIB}=7.62 \mathrm{~cm}$ (according to the utilization standard in Manitoba with the stump height of $15 \mathrm{~cm}$ ) is the $h_{m}$. In our calculation of $h_{m}$, a binary search algorithm, was employed to find the $h$ corresponding to $\mathrm{DIB}=7.62 \mathrm{~cm}$ in the range from 0 to $H$.

Log production was calculated based on the calculated $h_{m}$. The total log length was calculated by subtracting the stump height, which is also defined by the utilization standard for the province, and in our case it is $15 \mathrm{~cm}$ above ground in Manitoba. The length for each segmented log was defined by the sawmill utilization standard, which is $2.44 \mathrm{~m}$ in stud mills, and thus the number of segmented logs for each tree can be calculated as $\left(h_{m}-0.15\right) / 2.44$, and then truncated to an integer.

\section{Estimating lumber recovery using the Optitek software}

Lumber product recovery was defined as the percentage of the volume of final lumber products in the total log volume. At the individual tree level, it can be estimated using Optitek (Forintek Canada Corp. 2006), a software package developed by Forintek Canada Ltd., now part of the Forest Operations and Wood Products Division of FPInnovations. This software constructs a virtual tree, simulates the log flow in every step of sawmill operation, and optimizes the log bucking and cutting pattern processes, so that the output is the best combination of various end products based on either product volume or value. These output variables can thus provide estimates of lumber product recovery.

Optitek software requires log dimensions as input information (such as log length, diameters of large and small ends of the log for artificial logs, and scanned log dimensions from trees felled for lumber production in sawmills), and the output of Optitek include numbers of pieces of lumber in different product dimensions (thickness, width, and length), as well as product defects and mill residues. The input artificial log file for Optitek was calculated using a utility program that converts
$\mathrm{DBH}$ and $H$ of a log into its length, diameters of large and small ends using Kozak's taper model. In fact, any of the existing taper models can be applied to generate required log information for use in Optitek.

\section{Construction of response surfaces for potential lumber recovery}

The virtual tree constructed by Optitek represents the ideal situation (i.e., perfectly shaped tree form), in which no sweep or defects are considered. Sharma and Zhang (2004) demonstrated that the external tree profile reconstructed by Optitek accounts for up to $97.38 \%$ of total variation in squared DIB of black spruce along the stem. Therefore, for the purposes of the current study, the reconstructed external tree profile was regarded as accurate. This tree profile can then be processed according to the procedure for a Canadian stud mill, which entails processing a single log length of $2.44 \mathrm{~m}$ to produce an optimized bucking solution for the sawmill to convert the log into lumber. For each tree profile, Optitek simulates product volume and value yields for primary products (e.g., lumber) and by-products (e.g., chips and sawdust), as well as the number of lumber pieces for each dimension and grade and bucking solutions.

Optitek was applied to various combinations of $\mathrm{DBH}$ (from $9 \mathrm{~cm}$ to $40 \mathrm{~cm}$, at $1-\mathrm{cm}$ intervals) and $H$ (from $5 \mathrm{~m}$ to $25 \mathrm{~m}$, at 1-m intervals) (i.e., 672 combinations) to ensure consideration of all possible ranges of sizes of black spruce identified from the inventory plot data. A 95\% confidence band was applied to the relationship between $\mathrm{DBH}$ and $H$, to eliminate unrealistic combinations, such that 538 of these combinations were included in the sensitivity analysis.

\section{Sensitivity analysis of Kozak's taper model}

A sensitivity analysis determines how the optimal solution of cutting patterns for the logs with maximized volume or value recovery (model output) is affected by changes in the log dimensions (model input) and/or coefficients (model parameters), in order to determine which variables and parameters are the most important and most likely to affect system behavior and/or predictions of the model (Smith et al. 2008). It can be applied to either complex simulation models or single mathematical models. Cariboni et al. (2007) summarized available best practices to run a sensitivity analysis for ecological models and some possible approaches to incorporate uncertainty propagation, including parametric bootstrap (sampling with replacement of model parameters) and bootstrap of the modeling process (sampling with replacement of data). They described the major applications of sensitivity analyses such as "the identification of the most important factor/s ... for the prioritization of research"; and "screening non-influential factors in the model, i.e., identifying those factors that can be assigned to any given value in their domains without significantly increasing the output variance".

Various methods of sensitivity analysis exist for a single model (Rosenbaum 2005). The commonly used method is the one-way sensitivity analysis in which one parameter in the model is varied by a given amount ( $10 \%$ or $20 \%$ is often chosen) while keeping other parameters unchanged, and the impact that the change has on the model's results is examined. This method can help to assess which parameters have the greatest influence on a model's results, and allow more attention to be paid to these parameters in future research for justifying the research costs. This method was applied using Optitek for the prediction of two variables: the merchantable height, $h_{m}$, and the number of 
logs produced by an individual tree, including partial logs that were sent for processing as chips. Other amounts of parameter changes could be used, including the $95 \%$ confidence limit for each of the individual parameters.

For models with more than a single parameter, the parameters are usually correlated to a certain degree, and this could cause the results from a one-way sensitivity analysis not to be fully adequate. This possible consequence has been investigated for the Kozak's taper model using Monte Carlo simulation (Kozak 1997), and the results indicated that "the predictive accuracy for total tree volume, merchantable height, and inside bark diameter is not affected", and the "predictions are unbiased even if the taper model has severe multicollinearity and autocorrelation". Given the small variations for each parameter of Kozak's taper model reported in the literature (e.g., Kozak 1988, Huang 1994, Muhairwe et al. 1994, Kozak 1998, Huang et al. 1999, Klos et al. 2007), the issue of correlated parameters in the Kozak's taper model was assumed to be insignificant in influencing the qualitative results of the one-way sensitivity analysis.

The other type of sensitivity analysis is the probabilistic sensitivity analysis, in which the model input is sampled from a given probability distribution of observed variables for examining how the randomness in model input and assumed probability distribution of the variables could affect the model predictions. This method was applied in the current study for examining the sensitivity of predicted lumber volume recovery at the stand scale to variations in model input by means of simulation. In the current study, 20 tree lists (which can be considered to be sufficient replication, since 10 replications have usually been considered as appropriate in most simulation research) were generated by means of a stochastic simulation of stand structure with a fixed number of trees (i.e., 200 trees per list, with 50 to 150 trees measured in most of our inventory plots in mind, for a total of 4000 trees). Each tree in a given tree list was assigned a $\mathrm{DBH}$ according to either a uniform (mean $=15 \mathrm{~cm}$ with a min of $7 \mathrm{~cm}$ and a max of $23 \mathrm{~cm}$ ) or a Weibull probability distribution estimated from the data from our study area (with parameters $\beta=1.1607, \eta=4.239$, and $\gamma=7.0824$ ). The corresponding $H$ for each tree was estimated from the regression equation between $\mathrm{DBH}$ and $H$. The total lumber recovery was calculated for each of the tree lists by summing lumber recovery over all trees.

The response surfaces constructed from the results of Optitek model simulations were essential for our sensitivity analysis for lumber volume recovery. To estimate lumber volume recovery, the required input data were the measurements of $\mathrm{DBH}$ and $H$ for individual trees, and the approximate estimations (after rounding the real $\mathrm{DBH}$ and $H$ to the nearest integers in $\mathrm{cm}$ and $\mathrm{m}$ ) can be obtained quickly from the response surfaces.

The sensitivity analysis used the parameters in Kozak's tree taper model for black spruce (Klos et al. 2007). One-way sensitivity analyses were performed, in which one of the eight parameters in the taper model was increased or decreased by $10 \%$ while the other parameters were kept unchanged. The results are presented in terms of average percent changes for all realistic combinations of $\mathrm{DBH}$ and $H$. The sensitivity can be calculated as follows:

$$
\begin{aligned}
& S_{\hat{y} r,+10 \%}=\frac{100}{n} \sum_{i=1}^{n}\left(\hat{y}_{+10 \%, i}-\hat{y}_{\text {Original }, i}\right) / \hat{y}_{\text {Original }, i} \\
& S_{\hat{y},-10 \%}=\frac{100}{n} \sum_{i=1}^{n}\left(\hat{y}_{-10 \%, i}-\hat{y}_{\text {Original }, i}\right) / \hat{y}_{\text {Original }, i}
\end{aligned}
$$

where $\hat{y}$ is the predicted variable (merchantable height $\left(h_{m}\right)$, number of logs produced, or lumber recovery); $\hat{y}_{+10 \%, i} \hat{y}_{-10 \%, i}$, and $\hat{y}_{\text {Originali } i}$ are the $i_{\text {th }}$ samples of a predicted variable with $10 \%$ increase, $10 \%$ decrease, and no change in taper model parameters, respectively; $S_{\hat{y} r+10 \%}$ and $S_{i r,-10 \%}$ are the average sensitivities (\% change) of a predicted variable with $10 \%$ increase and $10 \%$ decrease in taper model parameters, respectively; and $n$ is the total number of samples examined (538 for $h_{m}$ and number of logs produced and 4000 for lumber recovery, as described below).

\section{Results}

\section{Relationship between DBH and $H$ of black spruce}

A strong correlation was observed between measurements of $\mathrm{H}$ and DBH for black spruce in our study area. Nonlinear regression analysis yielded the following equation $\left(R^{2}=0.7535\right.$, $p<0.0001)$

$$
H=1.598565 \times D B H^{0.795605}
$$

With the 95\% confidence limit shown in Fig. 2, reasonable combinations of $\mathrm{DBH}$ and $H$ were identified for eliminating unrealistic Optitek simulations (reduced from 672 to 538 combinations in the simulations). In all the 10338 black spruce trees measured in our study area, the majority of combinations of DBH and $H$ were within the confidence limit as shown in Fig. 2.

The $R^{2}$ value from the parameter estimation could be improved by applying mixed-effect modeling technology (e.g., Sharma and Parton 2007, Crecente-Campo et al. 2010). However, the quality of model fit might not necessarily reflect the quality of predictions (e.g., Myers 1990); for our research purpose the predictability of eq. 5 was satisfactory.

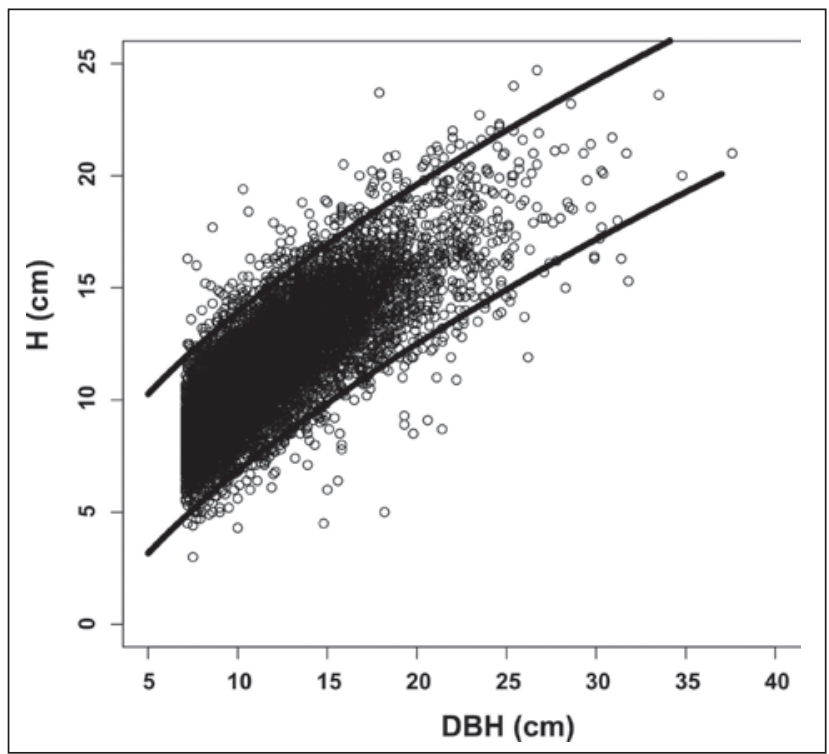

Fig. 2. Realistic combinations of black spruce's DBH and $H$ identified by a $95 \%$ confidence limit for the inventory plot data in the study area (10 338 individual trees in total). 


\section{Response surfaces for lumber recovery}

The lumber volume recovery in $\mathrm{m}^{3}$ can increase approximately linearly with increasing DBH as shown in the left surface of Fig. 3. It also increases linearly with increasing $H$, though with a lower rate of increase. However, the percentage of lumber recovery in relation to total log volume has different patterns of increase compared with the lumber volume recovery. When $\mathrm{DBH}$ is smaller than $20 \mathrm{~cm}$, the percentage of total log volume that can be used for lumber products increases rapidly with the increasing $\mathrm{DBH}$. In other words, the monetary value of lumber products will increase rapidly because of the large increase of the percentage of log volume that can be used in lumber products, which will contribute more revenue than that of log volume being used for chips. Nevertheless, when DBH is greater than 20 $\mathrm{cm}$, the percentage of total log volume that can be used for lumber products could have small variations within a range of $70 \%$ to $80 \%$. This suggested that the increase of monetary value of lumber products might not be proportional to the increase of lumber volume.

\section{Sensitivity of Kozak's taper model}

There were large changes in merchantable tree height and log production with an increase and decrease of $10 \%$ for parameters $a_{1}$ and $a_{2}$ (Table 2).

The results from the probabilistic sensitivity analysis on predictions of lumber recovery indicated that sensitivity changes occurred with a $10 \%$ decrease in parameter $a_{2}$ for both lumber recovery volume and lumber recovery percentage when $\mathrm{DBH}$ followed a uniform probability distribution (Table 3). However, when DBH followed a Weibull probability distribution, there was a only change in lumber volume recovery when $a_{2}$ was decreased by $10 \%$ (Table 4 ).

Our results indicate that different attributes (merchantable tree height, log production, and lumber volume recovery) that were predicted using Kozak's taper model had different levels of sensitivity to changes in the taper model parameters. The sensitivity of predicted variables to taper model parameters may vary when the model is used for different purposes. When used to predict merchantable height, $h_{m}$, or number of logs, small changes in two of the parameters could lead to larger differences in estimated values. Since the stump height of $15 \mathrm{~cm}$ and the log length of $2.44 \mathrm{~m}$ used in our analysis were defined by the sawmill utilization standard, any single tree with a merchantable height $h$ between $7.47 \mathrm{~m}(2.44 \times 3+0.15)$ and $9.90 \mathrm{~m}$ $(2.44 \times 4+0.15-0.01)$ (without the 0.01 reduction, four logs will be produced from a mathematical perspective) will produce three logs. Increasing $h_{m}$ within this range will probably contribute to an increase in residues of chips and biomass, but not log production.

Lumber recovery, in terms of both volume and percentage of total merchantable volume, was influenced not only by merchantable tree height $h_{m}$ but also by total merchantable volume resulting from changes in $h$. With an increase in tree DBH (and thus in $H$ ), the merchantable volume increases closer to the square of the DBH. Therefore, the frequency distribution of $H$ at a plot or stand level will affect predicted total merchantable volume, as indicated by lumber recovery. We tested this in our sensitivity analysis by assuming that tree DBH follows either a uniform or a Weibull probability distribution. Whereas equal weighting is applied to different $\mathrm{DBH}$ values when a uniform DBH distribution is assumed, unequal weights are applied to different $\mathrm{DBH}$ values when a Weibull $\mathrm{DBH}$ distribution is assumed. Since smaller weightings will be applied to small and large trees at opposite tails under a Weibull DBH distribution, the average sensitivity was expected to be smaller than that under a uniform DBH distribution, and our results confirmed this expectation (comparing Tables 3 and 4).

\section{Discussion}

Utilization of computerized optimization of sawmill operation

To predict the potential lumber product recovery that is one of the most important variables of forest managers, this study employed an industrial software package, Optitek. Before the era of computerized optimization technology being applied to forest product industry, this recovery was largely estimated by mill managers' experience, or using different scaling rules and assumptions, being generic and arbitrary (e.g., Wenger 1984, Avery and Burkhart 1994, Briggs 1994). One of the advantages of applying computerized optimization technology to the forest sector is its capability of dealing with most variables that affect the realization of potential lumber product recovery. However, the feasibility of applying computerized

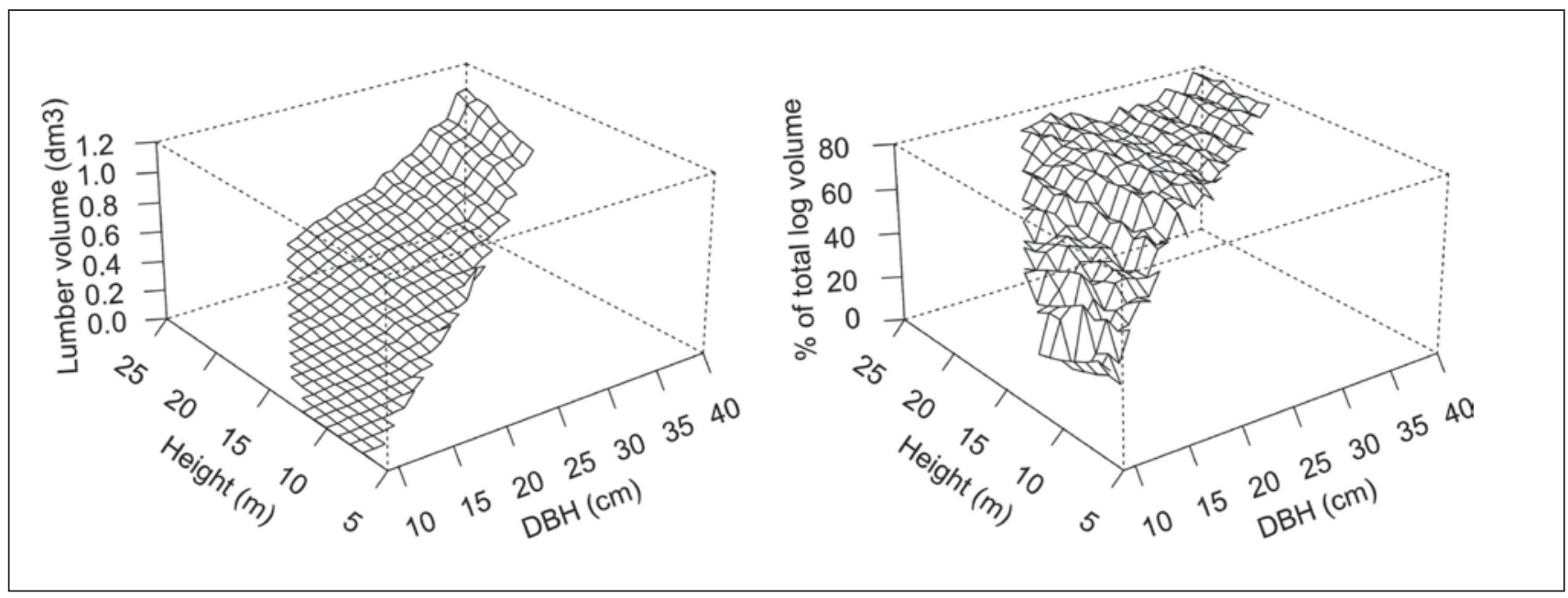

Fig. 3. Response surfaces of lumber volume recovery (left) and percentage of lumber recovery in relation to total log volume (right). 
Table 2. Sensitivity of parameters in Kozak's tree taper model in predicting tree height at a given top diameter inside bark (DIB) and log production

\begin{tabular}{lcc}
\hline & \multicolumn{2}{c}{ Mean change (\%) } \\
\cline { 2 - 3 } Sensitivity & $\begin{array}{c}\text { Merchantable } \\
\text { height }\end{array}$ & $\begin{array}{c}\text { Log } \\
\text { production }\end{array}$ \\
\hline$a_{0}+10 \%$ & 3.69 & 4.21 \\
$a_{0}-10 \%$ & -4.58 & -5.52 \\
$a_{1}+10 \%$ & $10.64^{\mathrm{a}}$ & $11.36^{\mathrm{a}}$ \\
$a_{1}-10 \%$ & $-14.44^{\mathrm{a}}$ & $-16.74^{\mathrm{a}}$ \\
$a_{2}+10 \%$ & $42.90^{\mathrm{a}}$ & $27.72^{\mathrm{a}}$ \\
$a_{2}-10 \%$ & $-91.16^{\mathrm{a}}$ & $-99.44^{\mathrm{a}}$ \\
$b_{1}+10 \%$ & -0.59 & -0.82 \\
$b_{1}-10 \%$ & 0.61 & 1.35 \\
$b_{2}+10 \%$ & -0.16 & -0.03 \\
$b_{2}-10 \%$ & 0.16 & 0.39 \\
$b_{3}+10 \%$ & -2.22 & -2.86 \\
$b_{3}-10 \%$ & 2.37 & 3.61 \\
$b_{4}+10 \%$ & 1.29 & 2.44 \\
$b_{4}-10 \%$ & -1.26 & -1.82 \\
$b_{5}+10 \%$ & -1.45 & -0.61 \\
$b_{5}-10 \%$ & 1.52 & 1.40 \\
\hline
\end{tabular}

${ }^{a}$ Sensitive change (> 10\%).

Table 3. Sensitivity of parameters in Kozak's tree taper model in predicting lumber recovery when diameter at breast height follows a uniform probability distribution

\begin{tabular}{lcc}
\hline & \multicolumn{2}{c}{ Mean change (\%) } \\
\cline { 2 - 3 } Sensitivity & $\begin{array}{c}\text { Lumber recovery } \\
\text { adjustment }\end{array}$ & $\begin{array}{c}\text { Lumber } \\
\text { recovery (as \%) }\end{array}$ \\
\hline$a_{0}+10 \%$ & 0.06 & 0.01 \\
$a_{0}-10 \%$ & -0.08 & -0.00 \\
$a_{1}+10 \%$ & 0.22 & 0.01 \\
$a_{1}-10 \%$ & -0.32 & -0.00 \\
$a_{2}+10 \%$ & 0.50 & 0.05 \\
$a_{2}-10 \%$ & $-91.71^{\mathrm{a}}$ & -15.19 \\
$b_{1}+10 \%$ & 0.22 & 0.01 \\
$b_{1}-10 \%$ & -0.32 & -0.00 \\
$b_{2}+10 \%$ & 0.22 & 0.01 \\
$b_{2}-10 \%$ & -0.32 & -0.00 \\
$b_{3}+10 \%$ & 0.22 & 0.01 \\
$b_{3}-10 \%$ & -0.32 & -0.00 \\
$b_{4}+10 \%$ & 0.22 & 0.01 \\
$b_{4}-10 \%$ & -0.32 & -0.00 \\
$b_{5}+10 \%$ & 0.22 & 0.01 \\
$b_{5}-10 \%$ & -0.32 & -0.00 \\
\hline
\end{tabular}

a Sensitive change (>10\%).

optimization technology in sawmill operations was significantly increased with the fast developments in information technology and computing power. With the two types of input log files, Optitek is capable of estimating lumber product recovery from the logs from felled trees transported to sawmills, as well as a possible supply of logs from the forest inventory following the procedure documented in the $\mathrm{BC}$ Ministry of Forests, Lands and Natural Resource Operations (2012).
Table 4. Sensitivity of parameters in Kozak's tree taper model in predicting lumber recovery when diameter at breast height follows a Weibull probability distribution

\begin{tabular}{|c|c|c|}
\hline \multirow[b]{2}{*}{$\begin{array}{c}\text { Sensitivity } \\
\text { adjustment }\end{array}$} & \multicolumn{2}{|c|}{ Mean change (\%) } \\
\hline & $\begin{array}{c}\text { Lumber } \\
\text { recovery }\left(\text { as } \mathbf{m}^{3}\right)\end{array}$ & $\begin{array}{c}\text { Lumber } \\
\text { recovery (as \%) }\end{array}$ \\
\hline$a_{0}+10 \%$ & 0.10 & -0.13 \\
\hline$a_{0}-10 \%$ & -0.15 & 0.11 \\
\hline$a_{1}+10 \%$ & 0.39 & -0.20 \\
\hline$a_{1}-10 \%$ & -0.67 & 0.34 \\
\hline$a_{2}+10 \%$ & 1.02 & -0.48 \\
\hline$a_{2}-10 \%$ & $-24.50^{\mathrm{a}}$ & -6.32 \\
\hline$b_{1}^{2}+10 \%$ & 0.39 & -0.20 \\
\hline$b_{1}-10 \%$ & -0.67 & 0.34 \\
\hline$b_{2}+10 \%$ & 0.39 & -0.20 \\
\hline$b_{2}-10 \%$ & -0.67 & 0.34 \\
\hline$b_{3}+10 \%$ & 0.39 & -0.20 \\
\hline$b_{3}-10 \%$ & -0.67 & 0.34 \\
\hline$b_{4}+10 \%$ & 0.39 & -0.20 \\
\hline$b_{4}-10 \%$ & -0.67 & 0.34 \\
\hline$b_{5}+10 \%$ & 0.39 & -0.20 \\
\hline$b_{5}^{5}-10 \%$ & -0.67 & 0.34 \\
\hline
\end{tabular}

${ }^{a}$ Sensitive change (> 10\%).

All software packages will have their strengths and weaknesses, and they were all developed for different purposes. Similarly, Optitek was developed for optimizing the operations of sawmills. Optitek is able to handle sweep and defects of logs in the optimization algorithm; however, since these are individual tree/log-based characterizations and cannot be generalized to even multiple trees of the same species in the same plot, it is inappropriate to perform such generalization in the virtual tree reconstruction. To ensure accuracy of the optimization, users need to fell the trees and scan their real stem forms, including defects, being used as Optitek input. The utilization of Optitek for our purpose is to assist the forest management planning process, as opposed to sawmill operation. In the planning process, it is neither environmentally desirable nor economically feasible to cut every tree for accurate estimation of potential products. Optitek simulations in the current study provide estimation of forest product recovery representing the theoretical or maximum rate under ideal conditions (i.e., straight logs without any defect, see Fig. 5), and forest managers will need to apply some reasonable discount that appears appropriate for their regions, or perform different scenario analyses. The preliminary results from other Optitek simulations showed that the percentage of lumber product recovery will decrease with increasing tree taper and/or sweep in $\mathrm{cm} / \mathrm{m}$, and the sawmill efficiency determined by the machine centre layout could further alter the results accordingly ( $\mathrm{Li}$, unpublished results), which suggests that further investigations into how other factors could affect Optitek simulation results will be needed.

Small changes in these response surfaces could be expected when performing Optitek simulations for random length mills, or for value maximizations. However, these changes might have less influence on our current research purpose because the basic patterns of these response surfaces will be unchanged. For example, the same Optitek simulations were also performed for a generic machine centre layout in random length mills, and the results displayed similar patterns of the response surfaces. 


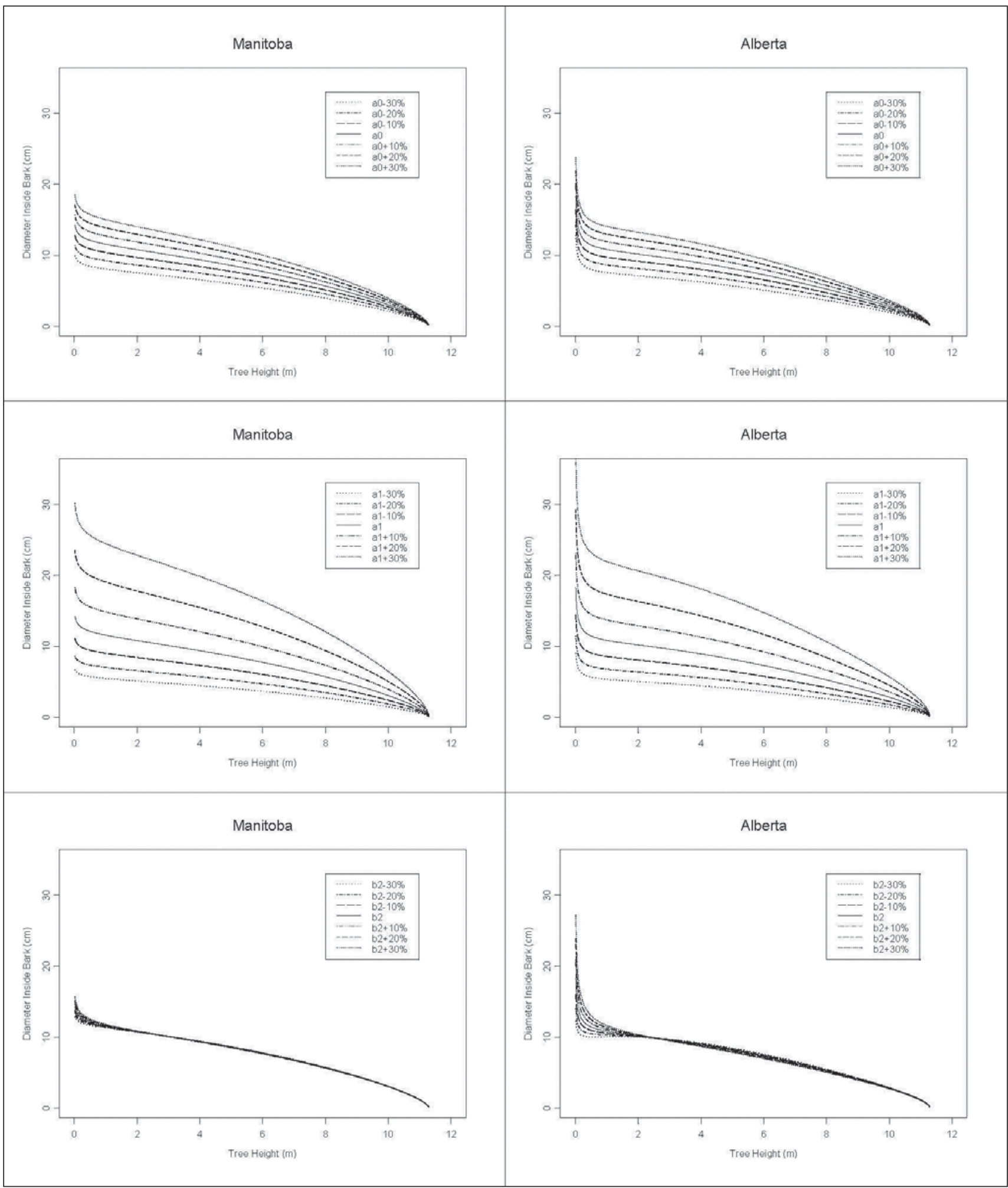

Fig. 4. Effect of increasing and decreasing $10 \%, 20 \%$, and $30 \%$ changes in parameter $a_{0}$, $a_{1}$, and $b_{2}$ of Kozak's taper model on the shape of DIB curve for an average black spruce tree in our study area $(H=11.3 \mathrm{~m})$.

Therefore, for the current purpose the scenario of stud mills was considered to be a reasonable representation of lumber production. Furthermore, there are more stud mills in northern Quebec than in southern Quebec (Pierre Bédard, FPInnovations, September 7, 2012, personal communication), which may suggest that the stud mills are more suitable for logs with relative smaller diameters-and black spruce has relatively smaller diameters than other major tree species such as Douglas-fir and white spruce. Nevertheless, it is a suitable topic for further examination to include trees with larger diameters. 


\section{Sensitivity analysis on Kozak's taper} model behavior

Application of the one-way sensitivity analysis to each of the eight parameters in Kozak's taper model is essential to examine how the uncertainties involved with changes in each parameter could alter the shapes of DIB curves (changes of diameters along the tree height), thus the yield of forest products. The 10\% change for each parameter in our analysis may or may not cover the entire ranges of parameter changes; however, our sensitivity analysis was carried out using the parameters from Klos et al. (2007), which was the only set of parameters for black spruce in Manitoba. By considering the parameters from Alberta data it was found that $b_{1}$ to $b_{5}$ have larger ranges of changes (>10\%), and $a_{2}$ has the smallest change (close to $0 \%$ ). Additional analyses were conducted using the average tree $(\mathrm{DBH}=11.7 \mathrm{~cm}$ and $H=11.3 \mathrm{~m})$ as an example as indicated in Table 5. As seen from the table, significant increases in log volume may not necessarily lead to the increase in lumber production recovery. We also examined results from $20 \%$ and $30 \%$ increases and decreases for the parameters. Using the average tree as an example again, the calculated DIB at $1.3 \mathrm{~m}$ of tree height from the original parameters for $b_{1}$ to $b_{5}$ is $11.3045 \mathrm{~cm}$, and the DIBs at $1.3 \mathrm{~m}$ of tree height from increases and decreases at $10 \%, 20 \%$, and $30 \%$ for $b_{1}$ to $b_{5}$ resulted in very small changes (from $11.104 \mathrm{~cm}$ to $11.5086 \mathrm{~cm}$ with an average of $11.30505 \mathrm{~cm}$ ). This suggested that up to $30 \%$ changes in $b$ to $b_{5}$ will not result in the changes of $\mathrm{DBH}$ class for a given $H=11.3 \mathrm{~m}$. This means that no change would be detected in log and lumber volume, and no change in $\%$ of lumber recovery from the Optitek predictions.

As an example, Fig. 4 shows the effect of changes in the parameters $a_{0}$, $a_{1}$, and $b_{2}$ of Kozak's taper model on the shape of DIB curve for an average black spruce tree in our study area with $H=11.3 \mathrm{~m}$, and Fig. 5 shows lumber

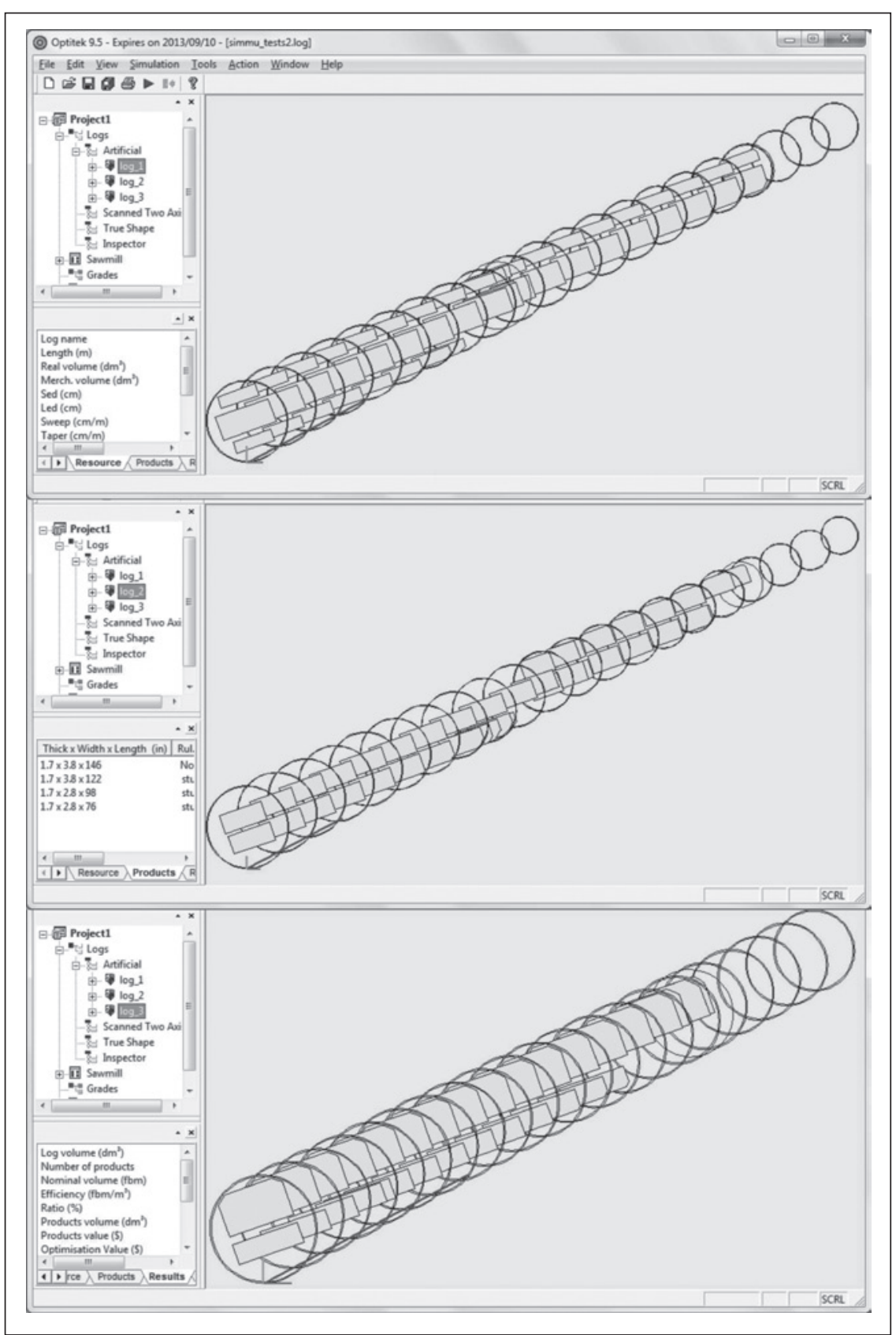

Fig. 5. Lumber products within a tree stem simulated by Optitek from varying $a_{0}$ for an average black spruce tree in our study area $(H=11.3 \mathrm{~m})$. The upper graph shows the five pieces of lumber from using the original $a_{0}$; the middle graph shows the four pieces of lumber from using a $10 \%$ increase in $a_{0}$; and the lower graph shows the two pieces of lumber from using a $10 \%$ decrease in $a_{0}$.

Table 5. Changes in DIB, log volume, log length, lumber volume and percentage of lumber for an average black spruce tree in our study area $[\mathrm{DBH}=11.7 \mathrm{~m}$ and $H=11.3 \mathrm{~m}$ )

\begin{tabular}{lcccccc}
\hline Items & $\begin{array}{c}\text { DIB at } \boldsymbol{h} \text { of } \\
\mathbf{1 3 0} \mathbf{~ c m}\end{array}$ & $\begin{array}{c}\text { Log volume } \\
\left(\mathbf{d m}^{\mathbf{3}}\right)\end{array}$ & $\begin{array}{c}\boldsymbol{h} \text { of DIB of } \\
\mathbf{7 . 6 2} \mathbf{~} \mathbf{m}\end{array}$ & $\begin{array}{c}\text { Log length } \\
(\mathbf{m})\end{array}$ & $\begin{array}{c}\text { Lumber volume } \\
\left(\mathbf{d m}^{3}\right)\end{array}$ & $\begin{array}{c}\text { Lumber } \\
(\mathbf{\%})\end{array}$ \\
\hline $\mathrm{a} 0$ & 11.3045 & 50.87 & 6.11 & 5.96 & 23.6 & 46.39 \\
$+10 \% \mathrm{a} 0$ & 12.4349 & 60.54 & 6.83 & 6.68 & 23.6 & 38.98 \\
$-10 \% \mathrm{a} 0$ & 10.174 & 42.04 & 5.14 & 4.49 & 17.7 & 42.10 \\
\hline
\end{tabular}


products within a tree stem simulated by Optitek from varying $a_{0}$. The upper graph shows the five pieces of lumber from using the original $a_{0}$; the middle graph shows the four pieces of lumber from using a $10 \%$ increase in $a_{0}$; and the lower graph shows the two pieces of lumber from using a $10 \%$ decrease in $a_{0}$. The differences in lumber product recovery are determined by the diameter at the large end of the log and log length, which are in turn determined by the taper model parameters.

The parameter $a$, has the smallest range of variation (almost $0 \%$ ) from Alberta data, and our sensitivity analysis results indicated that all three predicted variables are sensitive to changes in $a_{2}$. A $10 \%$ change in $a_{2}$ is much bigger than that observed in Alberta. In fact, the $a_{2}$ value reported in Klos et al. (2007) for Manitoba is very close to that observed in Alberta (0.9950 in Manitoba vs. 0.999640 in Alberta). As a result, the $10 \%$ change in $a_{2}$ is considered unrealistic; nevertheless, the qualitative conclusion was unchanged. For instance, using the average tree as an example again, we calculated the changes of DIB at $1.3 \mathrm{~m}$ tree height when $0.05 \%, 0.1 \%, 0.5 \%, 1 \%, 2 \%, 5 \%$, and $10 \%$ of changes are applied to $a_{2}$. As seen from the Fig. 6, the changes in $a_{2}$ altered the predicted DBH class substantially, causing large differences in percentage of lumber recovery. This suggested that the uncertainty involved in the estimated $a_{2}$ could result in substantial changes in predicted DBH class for a given tree $H$. However, in practice, the change in the estimated $a_{2}$ rarely exceeds $0.1 \%$.

Simulating a change in only one parameter does not mimic real differences on the overall model prediction. For this study, however, our research purpose is not to detect the overall impact when the parameters change together, rather, we focus on the impact of individual parameters. One interesting observation noticed in our study is that changing one parameter while fixing the remaining parameters likely represents an extreme condition, since corresponding changes in other parameters usually compensate or correct the extreme condition in some ways, hence reducing the possibility of altering the predicted DBH class in our study.

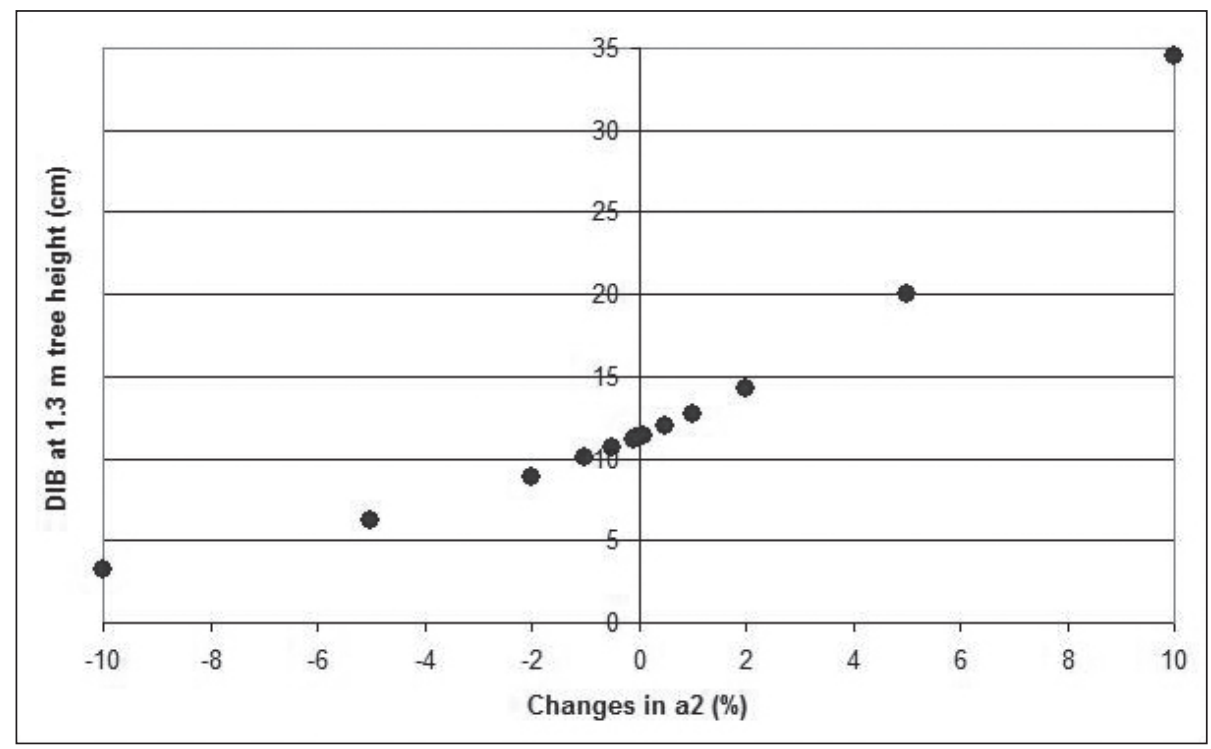

Fig. 6. Changes of DIB at $1.3 \mathrm{~m}$ tree height when increasing and decreasing $0.05 \%, 0.1 \%$, $0.5 \%, 1 \%, 2 \%, 5 \%$, and $10 \%$ of changes are applied to $a_{2}$ for an average black spruce tree in our study area $(H=11.3 \mathrm{~m})$.

\section{Management applications of the sensitivity analysis}

With the shifting of forest management from a volume-based to a value-based paradigm, more attention should be paid to the variables that contribute most to value estimation. In valuation of forest goods and services, potential lumber value recovery is suitable as the first product category to investigate because of the general expectation of higher economic return. In lumber value estimation, taper might be the variable contributing least to the accuracy of stand-scale valuation of lumber value recovery among $\mathrm{DBH}, H$, and taper. Using a large forest inventory data set from Manitoba, for example, Li et al. (2010) found that DBH contributed the most (73.5\%) to lumber value recovery, followed by $H(17.0 \%)$ and taper (9.4\%).

The results reported here indicate that the parameters in Kozak's taper model might contribute less to predicting lumber value recovery than merchantable tree height and log production, which in turn suggests the possibility of simplifying the procedure for reconstructing virtual profiles of individual trees. This simplification could reduce workload substantially in terms of required field sampling for different tree species in various locations across forest landscapes or eco-regions. This workload reduction would not only speed up processes for forest wood valuation but also conserve considerable resources for other needs, as well as applying to regions where regional taper models are not available (Ung et al. 2013). As such, it might be reasonable to develop a Canadian national-level version of Kozak's taper model to predict forest product variables such as log production and the percentage of lumber recovery across softwood species (or species groups) and geographic regions, though this might not be the only approach in such a development. Such a national-level taper model would allow forest product-based valuation at the regional or landscape scale to be simulated through reconstruction of stand structure on the basis of existing information in the forest inventory and the literature. More predicted variables that can be influenced by tree taper should be considered before developing such a national softwood taper model, such as Ung et al. (2013) conducted for pre-harvest estimation of sawlog volume. Accuracy is important, and so is precision. The accuracy and precision of the variable predictions using such a national-level taper model might not be as high as those tree species- and regional-specific taper models; however, the accuracy and precision could satisfy an acceptable level of estimating potential products recovery in large areas determined by the national or regional forest management agencies. Nevertheless, further investigations are needed, including comparison of predictions for other major tree species and different geographic regions.

In addition to the scenario tested in this sensitivity analysis, other wood utilization preferences exist, 
such as sending all harvested trees directly to pulp mills (as is done in our study area) or for use as fuel wood or as a biomass source for bioenergy or biorefinery processes. This could be of particular interest under current fluctuating market conditions for forest products.

The preceding evaluation and discussion are presented from the forest products perspective, especially consideration of physical dimensions of softwood lumber products. Evaluations from other perspectives should also be taken into account in making decisions related to forest resource management. These other perspectives include considerations that might relate to the quality of forest products, for example, the frequency and location of knots, which may be influenced by tree taper; the potential utilization of wood as a source of biomass, bioenergy, or substrate for biorefinery activities; potential utilization of standing forests for carbon credits (both sequestration and offset credits) in domestic and international carbon trading systems; non-timber values from unharvested forests; aesthetic values for ecotourism; and other goods and services, such as soil and water conservation, provided by forest ecosystems.

\section{Conclusions}

Inspired by existing research results for established tree taper models, our sensitivity analysis showed that predictions of merchantable height and log production are sensitive to two of the eight parameters in Kozak's taper model, whereas predictions of lumber recovery are sensitive to only one parameter. Given the relatively small variations in softwood tree taper parameters across Canada and the limited contribution of tree taper to characterizing the recovery of lumber value at the stand scale, the predictions of forest product variables such as log production and percentage of lumber recovery from forest inventory are not very sensitive to tree taper.

\section{Acknowledgements}

The authors thank the two anonymous reviewers and the Associate Editor for their constructive comments and suggestions on an earlier version of this manuscript; J. Liu, R. Klos, and G. Carlson of Manitoba Conservation for making the inventory plot data available to us; T. Zhang and C. Liu of the Forest Operations and Wood Products Division of FPInnovations for carrying out the Optitek model simulations; P. Bédard and J. Cool of the FPInnovations for supplying training and literature on Optitek; A. Groot of Canadian Wood Fibre Centre, B. Laishley of the Canadian Forest Service, and P. Robinson for their critical reading of and helpful comments on an earlier version of this manuscript.

\section{References}

Avery, T.E. and H.E. Burkhart. 1994. Forest Measurements. 4th Ed. McGraw-Hill, Boston, MA. 408 p.

Bi, H. 2000. Trigonometric variable-form taper equations for Australian Eucalypts. Forest Science 46(3): 397-409.

BC Ministry of Forests, Lands and Natural Resource Operations 2012. CGNF Compilation Standards for the Coast Forest Region. Timber Pricing Branch. Available at http://www.for.gov.bc.ca/hva/ manuals/cgnfcompilation.htm.

Briggs, D.G. 1994. Forest Products Measurement and Conversion Factors: with Special Emphasis on the U.S. Pacific Northwest. College of Forest Resources, University of Washington. 161 p. Available at http://www.ruraltech.org/projects/conversions/briggs_conversions/ briggs_book.asp> [Accessed 3 October, 2013].
Cariboni, J., D. Gatelli, R. Liska and A. Saltelli. 2007. The role of sensitivity analysis in ecological modeling. Ecological Modelling 203: 167-182.

Clark, A.C.III, R.A. Souter and B.E. Schlaegel. 1991. Stem profile equations for southern tree species. US For. Serv. South. Res. Pap. SE282. US For. Serv., Asheville, NC. 113 p.

Crecente-Campo, F., M. Tome, P. Soares and U. Die'guez-Aranda. 2010. A generalized nonlinear mixed-effects height-diameter model for Eucalyptus globulus L. in northwestern Spain. Forest Ecology and Management 259: 943-952.

Demaerschalk, J.P. and A. Kozak. 1977. The whole-bole system: a conditioned dual equation system for precise prediction of tree profiles. Canadian Journal of Forest Research 7(3): 488-497.

Forintek Canada Corp. 2006. Optitek user's manual. Forintek Canada Corp., Quebec, QC. 136 p.

Gal, J. and I.E. Bella. 1994. New stem taper functions for 12 Saskatchewan timber species. Natural Resource Canada, Canadian Forest Service, Northwest Region, Northern Forestry Centre, Edmonton, Alberta, Canada. Information Report NOR-X-338.

Hjelm, B. 2011. Taper and volume equations for poplar trees growing on farmland in Sweden. Thesis, Swedish University of Agricultural Sciences, Uppsala. Available at http://pub.epsilon.slu.se/8020/1/ hjelm_b_110429.pdf [Accessed 10 December 2012].

Huang, S. 1994. Individual tree volume estimation procedures for Alberta: methods of formulation and statistical foundations. Report \#1 in the Report Series: Ecologically Based Individual Tree Volume Estimation for Major Alberta Tree Species. Forest Management Division, Alberta Environment Protection, Edmonton, AB.

Huang, S., S. Titus, D. Price and D. Morgan. 1999. Validation of ecoregion-based taper equations for white spruce in Alberta. The Forestry Chronicle 75(2): 281-292.

Jiang, L., J.R. Brooks and G.R. Hobbs. 2007. Using crown ratio in yellow-poplar compatible taper and volume equations. Northern Journal of Applied Forestry 24: 271-275.

Klos, R.J., G.G. Wang, Q.L. Dang and E.W. East. 2007. Taper equations for five major commercial tree species in Manitoba, Canada. Western Journal of Applied Forestry 22(3): 163-170.

Kozak, A. 1988. A variable-exponent taper equation. Canadian Journal of Forest Research 18(11): 1363-1368.

Kozak, A. 1997. Effects of multicollinearity and autocorrelation on the variable-exponent taper functions. Canadian Journal of Forest Research 27(5): 619-629.

Kozak, A. 1998. Effects of upper stem measurements on the predictive ability of a variable-exponent taper equation. Canadian Journal of Forest Research 28(7): 1078-1083.

Kozak, A. 2004. My last words on taper equations. The Forestry Chronicle 80(4): 507-515.

Leites, L.P. and A.P. Robinson. 2004. Improving taper equations of loblolly pine with crown dimensions in a mixed-effects modeling framework. Forest Science 50: 204-212.

Li, C., H.J. Barclay, H. Hans, J. Liu, R. Klos and G. Carlson. 2010. Accuracy in population estimation: a methodological consideration. Ecological Complexity 7: 208-211.

Li, R., A. Weiskittel, A.R. Dick, J.A. Kershaw Jr. and R.S. Seymour. 2012. Regional stem taper equations for eleven confer species in the Acadian Region of North America: development and assessment. Northern Journal of Applied Forestry 29(1): 5-14.

Maguire, D.A. and J.L.F. Batista. 1996. Sapwood taper models and implied sapwood volume and foliage profiles for coastal Douglas-fir. Canadian Journal of Forest Research 26: 849-863.

Max, T.A. and H.E. Burkhart. 1976. Segmented polynomial regression applied to taper equations. Forest Science 22(3):283-289.

Morris, D.M. and R.R. Forslund. 1992. The relative importance of competition, microsite and climate in controlling the stem taper and profile shape in jack pine. Canadian Journal of Forest Research. 22: 1999-2003. 
Muhairwe, C.K., V.M. LeMay and A. Kozak. 1994. Effects of adding tree, stand, and site variables to Kozak's variable-exponent taper equation. Canadian Journal of Forest Research 24(2): 252-259.

Myers, R.G. 1990. Classical and Modern Regression with Applications. 2nd ed. PWS-KENT Publication Company, Boston, MA.

Newnham, R.M. 1988. A variable-form taper function. Can. For. Serv., Petawawa National Forestry Institute. Information Report PI-X-83.

Newnham, R.M. 1992. Variable-form taper functions for four Alberta tree species. Canadian Journal of Forest Research 22(2): 210-223.

Ormerod, D.W. 1973. A simple bole model. The Forestry Chronicle 49(3): 136-138.

Rosenbaum, P.R. 2005. Sensitivity analysis in observational studies. In B.S. Everitt and D.C. Howell (eds.) Encyclopedia of Statistics in Behavioral Science. 4: 1809-1814. John Wiley \& Sons. Ltd. Chichester, UK.

SAS Institute Inc. 1990. SAS/STAT User's Guide, 4th Ed., Version 6, vol. 1 \& 2. SAS Institute Inc., Cary, NC. 846 p.

Sharma, M. and J. Parton. 2007. Height-diameter equations for boreal tree species in Ontario using a mixed-effects modeling approach. Forest Ecology and Management 249: 187-198.
Sharma, M. and S.Y. Zhang. 2004. Variable exponent taper equation for jack pine, black spruce and balsam fir in eastern Canada. Forest Ecology and Management 198(1-3): 39-53.

Smith, E.D., F. Szidarovszky, W.J. Karnavas and A.T. Bahill. 2008. Sensitivity analysis, a powerful system validation technique. The Open Cybernetics and Systemics Journal 2: 39-56.

Ung, C.H., X.J. Guo and M. Fortin. 2013. Canadian national taper models. The Forestry Chronicle 89: 211-224.

Wang, D., H. Hsieh and S. Tang. 2007. Taper modeling on Taiwania plantation trees in the Liukuei area. Taiwan Journal of Forest Science 22(2): 339-353.

Wenger, K.F. (ed.) 1984. Forestry Handbook. 2nd Ed. John Wiley \& Sons, Inc. New York.1335 p.

Zakrzewski, W.T. 1999. A mathematically tractable stem profile model for jack pine in Ontario. Northern Journal of Applied Forestry 16: $138-143$. 